\title{
Experimental research to Optimize Process Parameters in Machining of Non Conducting Material with Hybrid Non Conventional Machining
}

\author{
Vikrant Sharma \\ Research Scholar \\ SGI Samalkha
}

\author{
Sunil Kumar \\ Assistant Prof., Dept. Of Mechanical Engineering, SGI \\ Samalkha
}

\section{ABSTRACT}

Among all non-conventional micro-machining,

\section{INTRODUCTION}

electrochemical discharge machining (ECDM) is having high quality of material removal rate with zero residual stress. This machining has been accepted as a highly modern technology in micromachining. In this paper an effort has been done on micro drilling of glass using electrochemical discharge machining (ECDM). A fixed tool and a step down transformer have been used to support the steady machining to increase the accuracy of work piece. The input parameters used in this experiment are voltage, concentration of electrolyte, enter- electrode gap and ratio of area of electrode. MRR has been investigated over the input parameters. Feed rate and electrolyte temperature has been made constant of $3 \mu \mathrm{m} / \mathrm{sec}$ and $30^{\circ} \mathrm{c}$ respectively. Taguchi method is used to optimize the effect of the process parameters on MRR. The signal to noise $(\mathrm{S} / \mathrm{N})$ ratio and the ANOVA analysis are employed to find the contributions of input parameters.

Keywords: Electrochemical Discharge Machining (ECDM), Taguchi Technique, ANOVA, Material Removal Rate (MRR), Sound vs. Noise $(\mathrm{S} / \mathrm{N})$ ratio

The electrochemical discharge machining (ECDM) have many applications for machining nonconducting engineering materials such as glass and ceramics. For electrically conductive materials, electrochemical machining (ECM) and electrical discharge machining (EDM) are two very powerful tools available. However several electrically nonconductive materials are also of great interest for many applications. Glass and composite materials are two examples. The technical requirements for using glass in micro systems are growing. Medical devices requiring biocompatible materials are only one of many examples. The importance of glass is also growing in the field of Micro Electro Mechanical Systems (MEMS) [1]. MEMS emerged in with the development of processes for the fabrication of micro structures.

Glass has some very interesting properties such as its chemical resistance or biocompatibility. As glass is transparent so it is widely used in optical applications or in applications where optical visualization of a 
process is needed. Some promising applications for glass in the MEMS field are micro accelerometers, micro reactors, micro pumps, and medical devices such as flow sensors or drug delivery devices. All these applications give birth to the need of effective and economical machining of glass.

To meet this need and industrial requirement of machining of brittle non-conducting materials, studies are needed to improve the quality characteristics of ECDM process. Thus parametric study has been carried out based on Taguchi method to optimize the machining characteristic MRR (material removal rate) for ECDM process by controlling three important machining parameters, such as applied voltage, electrolyte concentration and inter electrode gap.

ECDM has much more applications for machining non- conductive engineering materials like ceramics, fiber glass, etc. Such nonconductive materials have huge industries and commercial applications like Complex shaped micro- contours in insulators, Miniature features for turbine blades ( micro-tabulated cooling holes), Filters for food and textile industries, Micro fluidic channels in non-conducting materials (quartz, glass and ceramics), truing and dressing of metal bonded grinding tools etc. The current need for every industry is to improve the quality of machining of such non-conductive materials with minimum cost so as to compete on market and have maximum profit out of it. To meet these requirements on this particular machining process, research works is very much needed through correct parametric design and optimization technique. ECDM has the advantages over flexibility and simple procedure of machining, with great capability in micro-machining of nonconductive hard brittle materials.

\section{WHAT IS ECDM?}

ECDM Electro chemical discharge machining makes use of electrochemical and physical phenomena to machine glass. The principle is explained in the figure 1 below

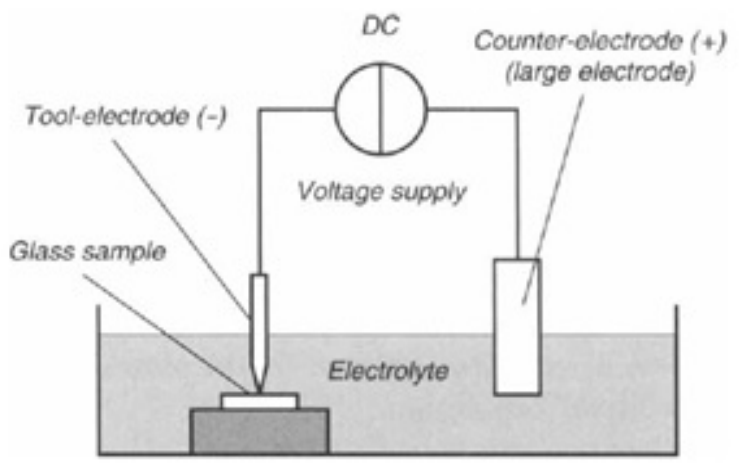

Figure 1-Schematic View of ECDM Process

The work piece is dipped in an appropriate electrolytic solution usually sodium hydroxide or potassium hydroxide. A constant DC voltage is applied between the machining tool or tool-electrode and the counter-electrode. The tool-electrode is dipped a few $\mathrm{mm}$ in the electrolytic solution and the counter-electrode is in general a large flat plate. The tool- electrode surface is always significantly smaller than the counter-electrode surface. The tool-electrode is generally polarized as a cathode, but the opposite polarization is also possible. When the cell terminal voltage is lower than a critical value called critical voltage, typically between 20 and $30 \mathrm{~V}$, traditional electrolysis occurs. [1] 
Hydrogen gas bubbles are formed at the tool-electrode and oxygen bubbles at the counter-electrode depending on their polarization and the electrolyte used. When the terminal voltage is increased, the current density also increases and more and more bubbles are formed. A bubble layer develops around the electrodes .The density of the bubbles and their mean radius increase with increasing current density. When the terminal voltage is increased above the critical voltage the bubbles coalesce into a gas film around the tool-electrode and produces the discharges between the tool and the surrounding electrolyte.

Machining is possible if the tool-electrode is in the near vicinity of the glass sample. During machining the local temperature can increase to such an extent, resulting in heat affected zones or even cracking. The different cathode and anode reaction takes place as soon as an appropriate potential is reached between the inter electrode gap of the machining zone [1]

Reactions at the cathode (or tool)

(i) Plating of metal ions

$$
M^{+}+e^{-} \rightarrow M
$$

Where $\mathrm{M}$ represents any anode material

(ii) Evolution of hydrogen gas.

$$
2 \mathrm{H}_{2} \mathrm{O}+2 e^{-} \rightarrow 2(\mathrm{OH})^{-}+\mathrm{H}_{2} \uparrow
$$

Reaction at anode (auxiliary electrode)

(i) Dissolution of metal ions in the electrolytic solution

$$
M \rightarrow M^{+}+e^{-}
$$

(ii) Evolution of oxygen gas at the auxiliary electrode

$$
4(\mathrm{OH})^{-} \rightarrow 2 \mathrm{H}_{2} \mathrm{O}+\mathrm{O}_{2}+4 e^{-}
$$

\section{FABRICATION OF SETUP}

The ECDM setup essentially requires a pulsed DC power supply, appropriate tool and auxiliary electrode, electrolyte and its container, work piece fixture and XYZ movement setting. As shown in Figure 2 below

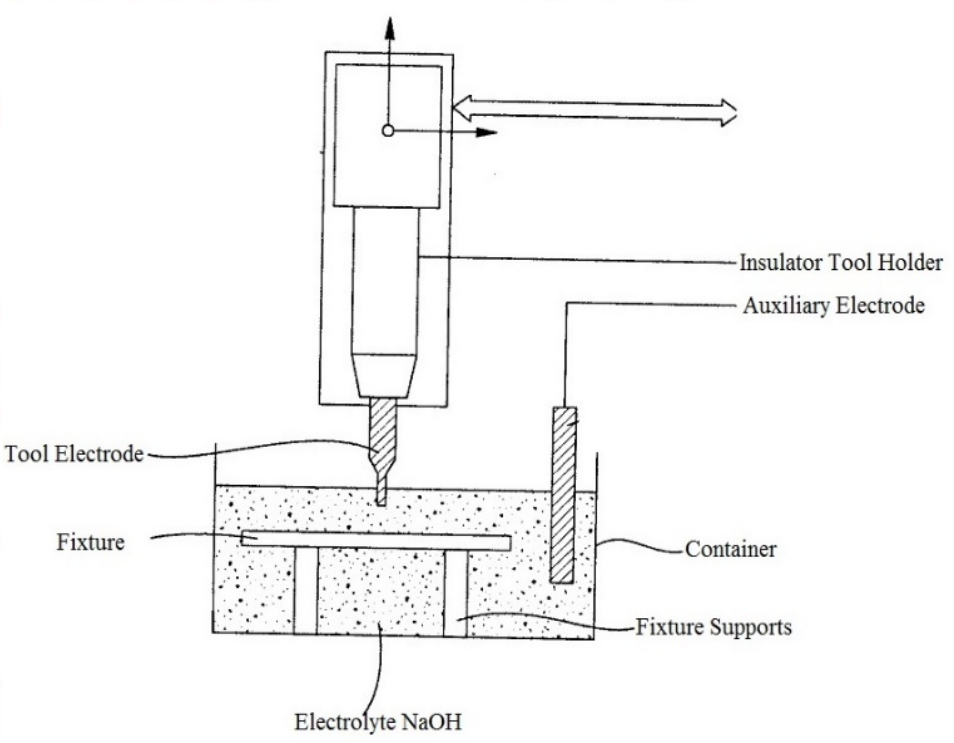

Figure 2

An AC to DC convertor with specific Voltage output range and voltage and current display is utilized as power supply with a dimmer to efficiently control the voltage. Electrolyte used is $\mathrm{NaOH}$ and is contained in a thick glass container. A spring managed tool of HSS of $0.9 \mathrm{~mm}$ diameter is used as tool electrode and is insulated in between by a fabric holder to avoid the rest of machine from circuit current. The table movements of a vertical milling machining is used to provide essential feeds. Work piece is glass with length $76 \mathrm{~mm}$ width $26 \mathrm{~mm}$ and thickness $1.35 \mathrm{~mm}$ .The fixture for holding the glass work piece is made of acrylic. Thus a working set up of ECDM is fabricated. 
Table 1: Machining parameters

\begin{tabular}{lllll}
\hline Symbols & Machining Parameters & Range & & \\
\hline A & Applied voltage V & 30 & 40 & 50 \\
\hline B & Electrolyte Concentration \% & $25 \%$ & $35 \%$ & $45 \%$ \\
\hline C & Inter Electrode Gap mm & 20 & 40 & 60 \\
\hline D & Ratio of Area of Electrode & $1: 20$ & $1: 40$ & $1: 60$ \\
\hline
\end{tabular}

\section{SELECTION OF PROCESS PARAMETERS}

In this present experimental work the process parameters are taken as voltage with different levels of $40 \mathrm{~V}$ to $60 \mathrm{~V}$, variable concentration of $\mathrm{KOH}$ as electrolyte with $40 \%$ to $45 \%$ by volume, inter electrode gap of $20 \mathrm{~mm}$ to $60 \mathrm{~mm}$ and ratio of area of electrode with 1:20 to 1:60.In designing the experiments these ranges are applied as in the table1 below.

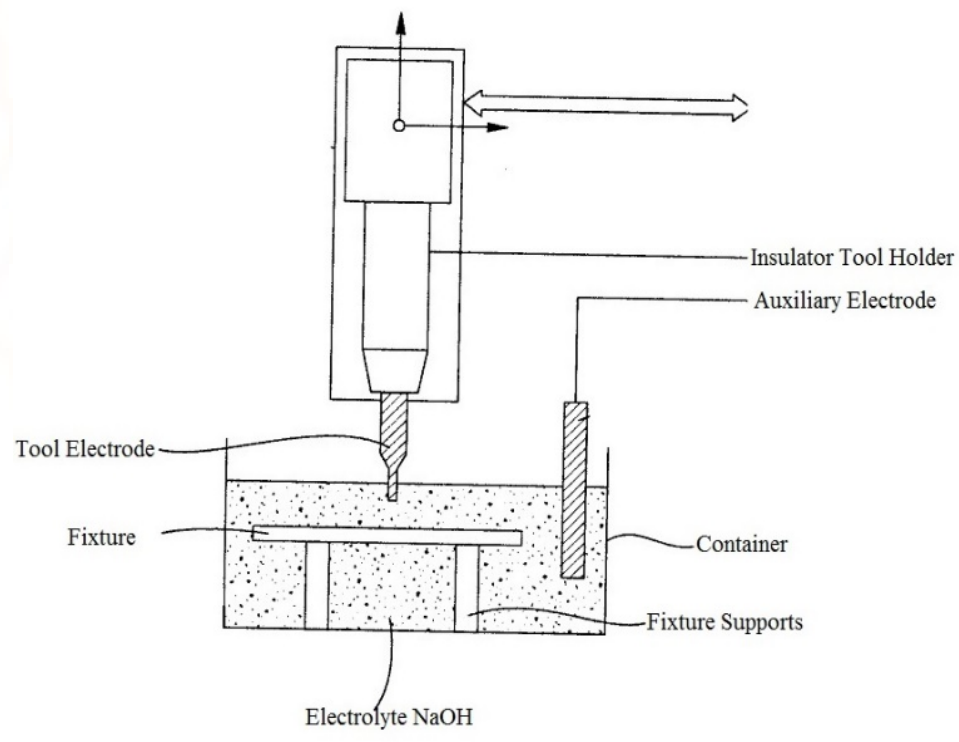

\section{MEASUREMENT OF PERFORMANCE}

Experiments are conducted according to the design of experiment and responses are measured for each experiment. The amount of material removed is measured by taking the difference in weight of the work piece before and after the machining $W_{1}$ and $W_{2}$ respectively. The MRR [8] can be calculated by dividing the difference in weight by machining time as $\left(W_{1}-W_{2}\right) / t . t$ denotes the machining time.

\section{TAGUCHI METHODOLOGY-BASED DOE}

The analysis of experimental results is done by Taguchi method [7] based parametric optimization technique to quantitatively determine the effects of various machining parameters on the MRR quality characteristics of ECDM process and to find the optimum parametric condition for obtaining optimum machining. In this analysis the design of experiment is done based on the selection of an appropriate standard orthogonal array. The analyses of signal-to-noise $\mathrm{S} / \mathrm{N}$ ratio and Pooled ANOVA [6] is carried out to study the relative importance of the machining parameters on MRR of ECDM process for machining non-conducting material glass and their respective contribution for machining is obtained. Based on this analysis the optimal setting for the machining parameters for MRR is obtained. 


\section{SELECTION OF ORTHOGONAL ARRAY}

Before selecting an orthogonal array for the experiment the total degrees-of-freedom [6] DOF for the experiments is to be calculated. The applied voltage, electrolyte concentration, inter electrode gap and Ratio of area of Electrode are the three factors and each factor has three levels. After calculating the total DOF of experiment the next is to select an orthogonal array. The standard orthogonal array which has at least three number of columns at three levels is $\mathrm{L}_{9}$ [6] is thus selected. This array has total eight DOF and it can handle four three-level machining parameters. Each machining parameter can be assigned to a column and nine machining parameter combinations are available in $\mathrm{L}_{9}$. Thus only nine experiments are required to be conducted to study the effects of machining parameters on the performance of ECDM process.

\section{ANALYSIS OF S/N RATIO}

In Taguchi method $\mathrm{S} / \mathrm{N}$ ratio [7] is used to measure the quality characteristics deviation from the desired value. The term signal represents the desirable mean value of the output response and the term noise represent the undesirable value the standard deviation for the output response. In present study to optimize the machining performance the larger the better quality characteristics for MRR is considered. The $\mathrm{S} / \mathrm{N}$ ratio for MRR, for $j^{\text {th }}$ experiment is defined as
$\mathrm{S} / \mathrm{N}$ ratio $=-10 * \log _{10}\left(\frac{1}{m} \sum_{i=1}^{m} 1 / \mathrm{R}^{2}\right)$

Where

$\mathrm{m}$ is the number of replications

$\mathrm{R}$ is the value of MRR of $\mathrm{i}^{\text {th }}$ replication test for $\mathrm{j}^{\text {th }}$ experimental condition.

Material removal rate is the main response which has to be taken seriously and has to be analyze carefully. It is defined as the total amount of material removed from the work piece per unit time after undergoing machining process. It is calculated as the difference of initial weight before machining to the final weight after machining of the work piece divided by total time taken to remove that amount of material.

\section{RESULTS AND DISCUSSION}

The Experiments are carried out as accordance to the designed DOE and all the nine combination of the conditions are repeated three times each. The result obtained and the calculated $\mathrm{S} / \mathrm{N}$ ratio is indicated in the table 2 below 
International Journal of Trend in Scientific Research and Development, Volume 1(4), ISSN: 2456-6470 www.ijtsrd.com

Table 2: DOE and results for MRR and S/N ratio

\begin{tabular}{|c|c|c|c|c|c|c|c|c|}
\hline \multicolumn{9}{|c|}{ Design of Experiments } \\
\hline $\begin{array}{l}\text { Expt } \\
\text { No. }\end{array}$ & $\begin{array}{l}\text { Applied } \\
\text { Voltage }\end{array}$ & $\begin{array}{c}\text { Electrolyte } \\
\text { Concentration }\end{array}$ & $\begin{array}{c}\text { Inter } \\
\text { Electrode }\end{array}$ & $\begin{array}{l}\text { Ratio of Area } \\
\text { of Electrode }\end{array}$ & & $\begin{array}{l}\text { MRR } \\
\mathrm{mg} / \mathrm{min}\end{array}$ & & $\begin{array}{l}\text { S/N } \\
\text { Ratio }\end{array}$ \\
\hline $\mathrm{J}$ & A & B & $\mathrm{C}$ & $1: 20$ & $\mathrm{R}_{1 \mathrm{j}}$ & $\mathrm{R}_{2 \mathrm{j}}$ & $\mathrm{R}_{3 \mathrm{j}}$ & \\
\hline 1 & 30 & 25 & 20 & $1: 40$ & 1.018 & 1.002 & 1.004 & 0.068 \\
\hline 2 & 30 & 35 & 40 & $1: 60$ & 1.002 & 1.364 & 1.366 & 2.713 \\
\hline 3 & 30 & 45 & 60 & $1: 60$ & 1.004 & 1.434 & 1.428 & 3.126 \\
\hline 4 & 40 & 25 & 40 & $1: 20$ & 1.37 & 1.55 & 1.526 & 3.738 \\
\hline 5 & 40 & 35 & 60 & $1: 40$ & 1.364 & 1.738 & 1.762 & 4.860 \\
\hline 6 & 40 & 45 & 20 & $1: 40$ & 1.366 & 2.338 & 2.336 & 7.389 \\
\hline 7 & 50 & 25 & 60 & $1: 60$ & 1.438 & 2.464 & 2.46 & 7.821 \\
\hline 8 & 50 & 35 & 20 & $1: 20$ & 1.434 & 2.79 & 2.798 & 8.926 \\
\hline 9 & 50 & 45 & 40 & $1: 20$ & 1.428 & 2.95 & 2.962 & 9.423 \\
\hline
\end{tabular}

L2-L1 is the effect occurs when corresponding parameter value changes from level 1 to level 2. L3L2 is the effect occurs when the corresponding parameters value changes from level 2 to level 3 .

Table.3: Value of Process Parameters at Different Level

\begin{tabular}{|c|c|c|c|c|c|c|c|c|}
\hline LEVEL & & AGE & ELI & $\begin{array}{l}\text { NC.OF } \\
\text { ROLYTE }\end{array}$ & ELEC & 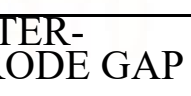 & RA & $\begin{array}{l}\text { OF AREA } \\
\text { CTRODE }\end{array}$ \\
\hline & $\begin{array}{l}\mathrm{S} / \mathrm{N} \\
\text { data }\end{array}$ & $\begin{array}{l}\text { Raw } \\
\text { data }\end{array}$ & $\begin{array}{l}\mathrm{S} / \mathrm{N} \\
\text { data }\end{array}$ & $\begin{array}{l}\text { Raw } \\
\text { data }\end{array}$ & $\begin{array}{l}\mathrm{S} / \mathrm{N} \\
\text { data }\end{array}$ & $\begin{array}{l}\text { Raw } \\
\text { data }\end{array}$ & $\begin{array}{l}\mathrm{S} / \mathrm{N} \\
\text { data }\end{array}$ & $\begin{array}{l}\text { Raw } \\
\text { data }\end{array}$ \\
\hline $\mathrm{LI}$ & 1.97 & 1.27 & 5.46 & 2.05 & 4.78 & 1.91 & 3.88 & 1.67 \\
\hline $\mathrm{L} 2$ & 5.33 & 1.88 & 5.29 & 1.95 & 5.97 & 2.06 & 5.50 & 1.97 \\
\hline L3 & 8.72 & 2.74 & 5.27 & 1.88 & 5.26 & 1.92 & 6.65 & 2.24 \\
\hline L2-L1 & 3.36 & 0.61 & -0.17 & -0.09 & 1.19 & 0.15 & 1.62 & 0.30 \\
\hline L3-L2 & 3.39 & 0.86 & -0.02 & -0.07 & -0.71 & -0.13 & 1.15 & 0.27 \\
\hline
\end{tabular}


Table 4: Results of Pooled ANOVA for MRR

\begin{tabular}{|l|l|l|l|l|l|l|l|}
\hline SOURCE & SS & DOF & V & P & SS' & F-Ratio & TABLE \\
\hline Voltage & 68.43 & 2 & 34.22 & 83.17 & 68.36 & 977.58 & 19 \\
\hline Concentration & 11.63 & 2.00 & 5.81 & 14.13 & 11.56 & 166.11 & 19.00 \\
\hline Electrode Gap & 0.07 & \multicolumn{7}{|c|}{ POOLED } \\
\hline Ratio of area & 2.1515 & 2 & 1.0757 & 2.6150 & 2.08 & 30.74 & 19 \\
\hline ERROR & 0.07 & 2 & 0.04 & 0.09 & 11.83 & & \\
\hline Total & 82.28 & 8 & & 100.00 & 82.28 & & \\
\hline
\end{tabular}

\section{DISCUSSION}

The effects of various process variables such as applied voltage, electrolyte concentration, inter electrode gap and ratio of area of electrode on material removal rate have been observed for obtaining the optimal machining characteristics of glass by using electrochemical discharge machining process. The influence of various process parameters and their effect on MRR has been analyzed on $\mathrm{KOH}$ as electrolyte.

\section{Effect of voltage on MRR:}

When the voltage increased, current starts flowing more rapidly along the circuit. This made the electrons gathered in more number near the tip of electrode in lesser time. As a result spark generated continuously and more rapidly, such that material started removing from the work piece. Effect of voltage on MRR:

When the voltage increased, current starts flowing more rapidly along the circuit. This made the electrons gathered in more number near the tip of electrode in lesser time. As a result spark generated continuously and more rapidly, such that material started removing from the work piece.

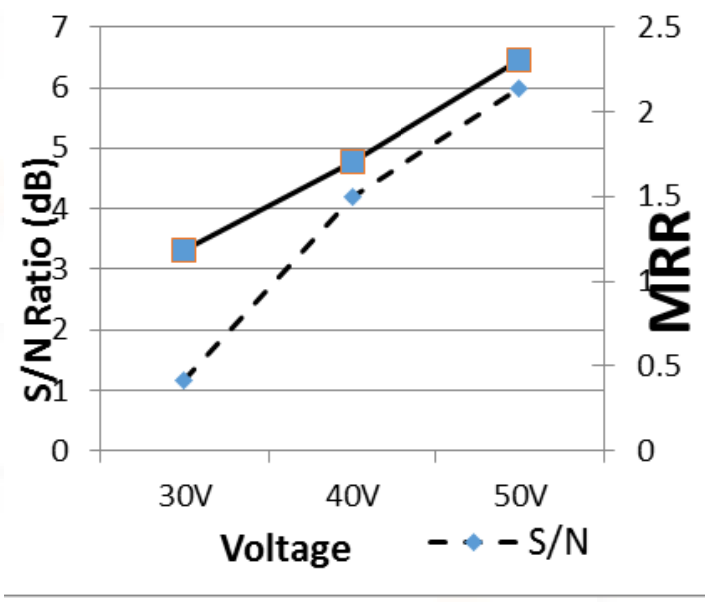

Graph 4.1 Effect of voltage on MRR

If we increase more voltage, it will generate more sparks per unit time and material will remove more quickly. It is done due to availability of increased energy that ionizes the gaseous layer at the cathode causing sparking. 
Effect of concentration of electrolyte on MRR:

On increasing concentration of electrolyte, number of

$\mathrm{OH}$ ion increased. As a result more hydrogen bubbles formed at the tip of cupper electrode. When this hydrogen bubbles splitted, spark generated. In other words increasing concentration of electrolyte, spark increased and MRR increased. MRR varies with concentration of electrolyte. As we can see in the graph, when concentration was about $25 \%$, the MRR was just about 4. It increases to 11 on increasing the concentration from $25 \%$ to $35 \%$. So MRR increases with increasing concentration of electrolyte. The above graph showing the effect of electrolyte concentration on MRR is for $\mathrm{KOH}$ electrolyte. It's highly reactive and with little increase in concentration can produce huge variation in MRR as we can analyses from the graph.

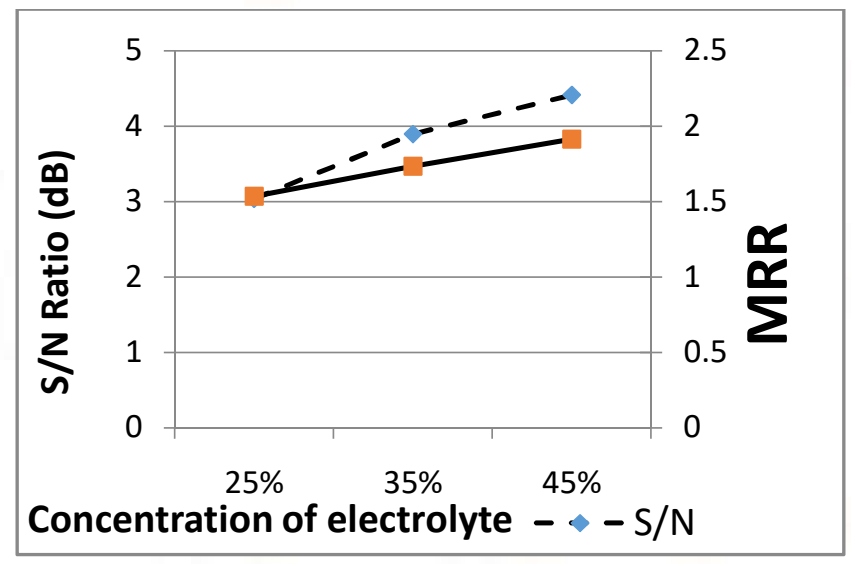

Graph 4.2 Effect of concentration of electrolyte on MRR

The above graph showing the effect of electrolyte concentration on MRR is for $\mathrm{KOH}$ electrolyte. It's highly reactive and with little increase in concentration can produce huge variation in MRR as we can analyses from the graph.

\section{Effect of inter-electrode gap on MRR:}

Form the graph 4.3 ; it can be notice that as the gap between cathode electrode and anode electrode increased beyond a certain value, the MRR starts decreasing. At $20 \mathrm{~mm}$, the evolved gases tend to stabilize the sparking process but at higher gap it will destabilize the sparking process and hence MRR decreases.

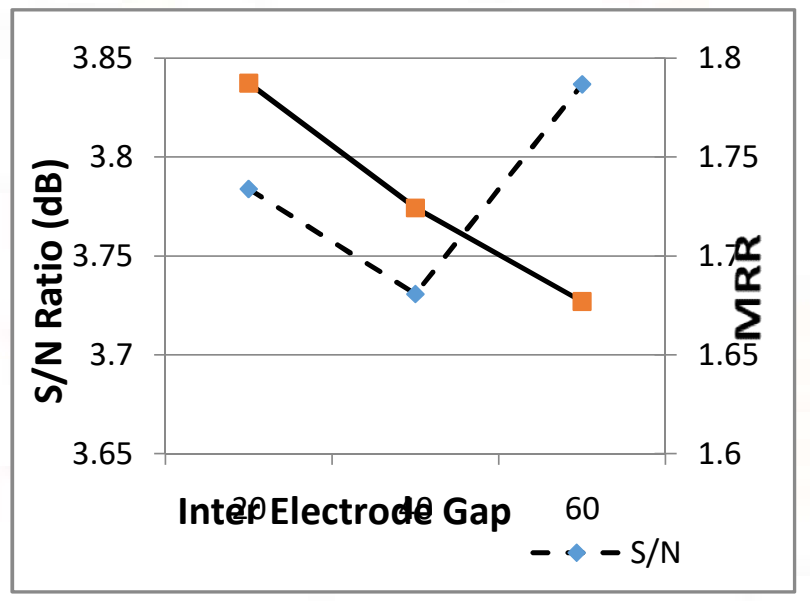

\section{Graph 4.3 effect of inter-electrode gap on MRR}

\section{Effect of ratio of area of electrode on MRR:}

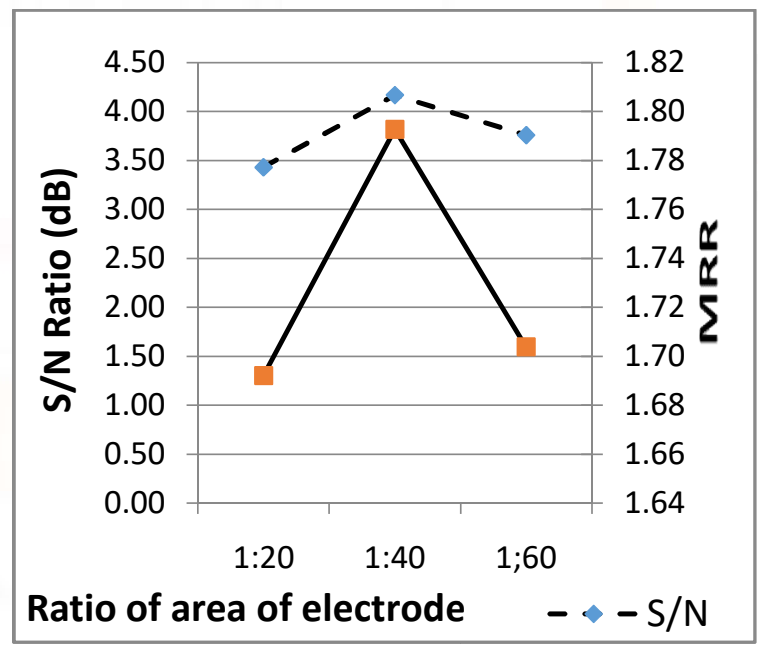

Graph4.4 effect of ratio of area of electrode on MRR 
It can be observed from graph 4.4 that as ratio of area of electrode increases i.e. area of cathode to area of anode ratio; MRR increases up to a certain value and then decreases. MRR is highest for the area ratio as $1: 40$.

\section{ANALYSIS}

To study the significance of the parameters, ANOVA is performed. The experimental design according to larger the better which preferred to maximize the result, and the ideal target value is infinity. To study the significance of the parameters, ANOVA was performed. It was noted that \% contribution of Voltage was highest (83.17) followed by concentration of electrolyte (14.13) and inter electrode gap (2.615).

Table V ANOVA Raw Data

\begin{tabular}{|l|l|l|l|l|l|}
\hline $\begin{array}{l}\text { Para } \\
\text { meter }\end{array}$ & SS & OF & V & P & F-Ratio \\
\hline V & 9.8066 & 2 & 4.9033 & 84.9130 & 79945.42 \\
\hline $\mathrm{C}$ & 1.4929 & 2 & 0.7464 & 12.9271 & 12170.87 \\
\hline $\mathrm{G}$ & 0.1256 & 2 & 0.0628 & 1.0875 & 1023.913 \\
\hline $\mathrm{R}$ & 0.12 & 2 & 0.061 & 1.06 & 1000.57 \\
\hline Error & 0.00 & 18 & 0.000 & 0.01 & \\
\hline Total & 11.5490 & 26 & & 100.0000 & \\
\hline
\end{tabular}

Where, SS-sum of square, DOF-degree of freedom And V-variance. F critical $=19.00$

\section{CONCLUSION}

From this experimental research few points were noticed:

\section{REFERENCES}

1. Rolf Wiithrich : "Micromachining using electrochemical discharge phenomenon "

2. Bhattacharyya, B.N. Doloi, S.K. Sorkhel : "Experimental investigations into electrochemical discharge machining (ECDM) of non-conductive materials"

3. Alakesh Manna ,Vivek Narang : "A study on micro machining of e-glass-fibre-epoxy composite by ECSM process"

4. Chenjun Wei \& Kaizhou Xu \& Jun Ni : “A finite element based model for electrochemical discharge machining “.

5. R. Wuthrich, V. Fascio : "Machining of nonconducting materials using electrochemical discharge phenomenon-an overview"

6. Montgomery D. "Design and analysis of experiments (2001)", John Willey and Sons, New York

7. Ross P.J. "Taguchi Techniques for quality engineering (1996)", McGraw Hill, New York

8. Amitabha Ghosh :'Electrochemical discharge machining: Principle and Possibilities “

9. Alakesh Manna \& Vivek Narang "A study on micro machining of e- glass-fibre-epoxy composite by ECSM process" Int $\mathrm{J} A d v$ Manuf Techno (2012) 61:1191-1197 DOI10.1007/s00170-012-4094-3; @SpringerVerlag London Limited 2012; Received: 6 June 2011/Accepted: 4 January 2012.-1096. 
International Journal of Trend in Scientific Research and Development, Volume 1(4), ISSN: 2456-6470 www.ijtsrd.com

Received in 7 May 2010; Accepted 20August 2010.459-465; Received 18 August 2008; accepted 9 Jan 10 M. Coteaţă, L. Slătineanu, O. Dodun, Ciofu C ,(2008), Electrochemical discharge machining of small diameter holes, Technical University of Gh. Asachi Iaúi.

10. Zhi-Wen Fan \& Lih-Wu Hourng, (2011), Electrochemical micro-drilling of deep holes by rotational cathode tools, Int J Adv Manuf Techno, 52, p.555-563.

11. Cheng-kuang Yang, Chih-Ping Cheng, ChaoChuang Mai and his co-researchers, (2010), effect of surface roughness of tool electrode materials in ECDM performance, International Journal of Machine Tools and Manufacture, 50, p.1088-1096.

12. Xuan Doan Cao, Bo Hyun Kim, Chong Nam chu,(2009), Micro-structuring of glass with features less than $100 \mu \mathrm{m}$ by electrochemical discharge machining" Precision Engineering, 33, p.459-465.

13. Min Seop Han, Byung-Kwon Min, Sang Jo Lee, (2011), Micro-electro discharge cutting of glass using a surface-textured tool" CIRP Journal of Manufacturing Science Technology, 4, p.362-369.

14. Cheng-Kuang Yang, Kun-Ling $\mathrm{Wu}$, JungChou Hung, Shin-Min Lee, Jui-Che Lin, Biing-Hwa Yan., (2010), Effect of process parameters on surface finishing through electrochemical discharge machining using quartz material. International Journal of Machine Tools and Manufacture 50, p.10881096.
15. B. Doloi, B. Bhattacharyya and S. K. Sorkhel (1999), Electrochemical Discharge Machining of Non-Conducting Ceramics, Defence Science Journal, 49, p. 331-338.

16. M. G. Mostofa, Mohammad Malekian, Simon S. Park \& Martin B. G. Jun, (2012), Micromechanical machining of soda lime glass, Int J Adv Manuf Techno, 48, p. 48454849.

17. Jana D. Abou Ziki, Tohid Fatanat Didar, Rolf wuthrich, (2012), Micro-texturing channel surfaces on glass with spark assisted chemical engraving, International Journal Of Machine Tools and Manufacture, 57, 66-72. 